\title{
Treatment outcomes in malignant ovarian germ cell tumors
}

\author{
Ram Kumar B.* \\ Department of Medical Oncology, Institute of Obstetrics and Gynecology, Madras Medical College, Chennai, Tamil \\ Nadu, India
}

Received: 19 October 2017

Accepted: 27 October 2017

\section{*Correspondence:}

Dr. Ram Kumar B

E-mail: ramkb68@rediffmail.com

Copyright: (c) the author(s), publisher and licensee Medip Academy. This is an open-access article distributed under the terms of the Creative Commons Attribution Non-Commercial License, which permits unrestricted non-commercial use, distribution, and reproduction in any medium, provided the original work is properly cited.

\section{ABSTRACT}

Background: Malignant ovarian germ cell tumours are rare group of ovarian neoplasms derived from primordial germ cells of the ovary. Objective of present study was to evaluate the outcome of treatment in malignant germ cell tumours.

Methods: 21 Patients of malignant ovarian germ cell tumours registered at Department of Medical Oncology, Institute of Obstetrics and Gynaecology, Chennai for the period from January 2012 to December 2015 were retrospectively analyzed for treatment outcomes.

Results: The median age at presentation was 21 years with age range between 14 and 40 years. 9patients (43\%) presented with mixed germ cell tumour, 6 patients (29\%) with dysgerminoma, 3 patients (14\%) with yolk sac tumour and 3 patients (14\%)with mature cystic teratoma. 13 patients $(62 \%)$ presented with Stage I disease, 5 patients $(24 \%)$ with Stage III and 3 patients (14\%) with Stage II. Fertility sparing surgery was done in 15 patients (71\%), and 4 patients (19\%) who completed family had TAH with BSO done. Adjuvant Chemotherapy was given for 16 patients (76\%) and as Neoadjuvant in 2patients (10\%) who had biopsy alone performed. 4patients (19\%) developed recurrence and was taken for salvage PVI chemotherapy.

Conclusions: Malignant ovarian germ cell tumours are relatively uncommon neoplasms characterized by high chemo sensitivity. This study confirms that malignant ovarian germ cell tumours have excellent prognosis and the effectiveness of BEP chemotherapy regimen. Fertility sparing surgery is feasible in most cases. Advanced Stage configured as an important risk factor for survival. The chemotherapy regimen was associated with significant but manageable toxicity.

Keywords: BEP Chemotherapy, Malignant ovarian germ cell tumour, Surgical treatment, Salvage Chemotherapy

\section{INTRODUCTION}

Malignant ovarian germ cell tumours are rare group of ovarian neoplasms derived from primordial germ cells of the ovary. ${ }^{1}$ It occurs in younger women with a peak incidence in women in their early twenties, representing $70 \%$ of neoplasm in this age group. ${ }^{2}$ It is often possible to cure these malignancies while preserving fertility, which is an especially important consideration given the young age of most patients. In contrast to epithelial ovarian cancer, germ cell tumours are diagnosed in Stage $I$ in $50 \%$ to $70 \%$ of cases and even in advanced stage, survival rates are encouraging ranging between $60 \%$ and $80 \% .^{3}$ Bilateral ovarian involvement in most germ cell tumours is uncommon.

The WHO classification for germ cell tumours are broadly divided into dysgerminoma which is the female counterpart of male seminoma and nondysgerminoma which includes yolk sac tumour, embryonal carcinoma, teratomas, nongestational choriocarcinoma. ${ }^{4}$

Abdominal pain, abdominal distension, pelvic fullness and urinary symptoms are common in patients with germ 
cell tumours of ovary. Rarely patients present with acute abdomen due to rupture, hemorrhage or ovarian torsion.

Patients frequently have a palpable adnexal mass that is typically evaluated by transvaginal ultrasound which may show a complex cyst comprising of solid and cystic regions.

Serum levels of Alfa-feto-protein(AFP), beta-human chorionic gonadotropin (b-HCG), are often helpful in recognizing the presence of endodermal sinus tumour (AFP elevation only), embryonal carcinoma (both AFP and b-HCG elevation) or choriocarcinoma (b-HCG elevation only). Patients with pure immature teratoma of ovary typically have normal values of AFP and b-HCG. Measurement of AFP and b-HCG levels is also useful to gauge the effectiveness of postoperative therapy and in monitoring disease recurrence. ${ }^{5}$

The initial approach for patient suspected of having ovarian germ cell tumours is surgery both for diagnosis and for therapy, including detailed inspection, palpation and if necessary staging biopsies and peritoneal wash to thoroughly determine the disease extent. ${ }^{6}$

The introduction of platinum based combination chemotherapy has represented the turning point in the treatment history of disease, extending the survival rates of early germ cell tumours to approximately $100 \%$ and even in advanced stage to $75 \% .^{7}$ At present multimodality treatment with initial surgery followed by platinum based combination chemotherapy (BEP) is regarded as the standard of care for germ cell tumours of ovary except for Stage Ia Dysgerminoma and Stage Ia Immature teratoma, Grade I in where surgery alone represents the treatment of choice. ${ }^{8}$

The MD Anderson cancer centre group began to use BEP combination chemotherapy for patients with metastatic dysgerminoma in 1984 and subsequently reported their findings with all $14 \mathrm{BEP}$ treated patient's disease free at a median follow-up of 22.4 months. ${ }^{9}$ The GOG also reported their experience of 20 patients with incompletely resected dysgerminoma who received either PVB or BEP and with a median follow up 26 months, 19 of 20 patients were disease free. ${ }^{10}$

Cushing et all reported 44 patients with completely resected ovarian immature teratoma, grade I through grade III (31 pure and 13 with yolk sac elements). The 4year event free and overall survival rates for the two groups were $97.7 \%$ and $100 \%$ respectively. ${ }^{11}$

The Children oncology group is currently studying the approach of surgery followed by surveillance in patients with Stage I germ cell tumour of ovary. Although this strategy appears to be promising, further study particularly in adult patients is warranted to ensure the safety and efficacy.

\section{METHODS}

This study is a hospital based retrospective study carried out at Department of Medical Oncology, Institute of Obstetrics and Gynaecology, Madras Medical College, Chennai, Tamil Nadu, India.

All cases of malignant germ cell tumors registered between January 2012 and December 2015 were analyzed for clinical presentation, tumour markers, stage at presentation, surgical procedure, pathology, systemic chemotherapy, outcomes and toxicity to treatment. Patients tumour were staged according to International Federation of Gynaecology and Obstetrics (FIGO).

21 patients of malignant germ cell tumours were registered between 2012 and 2015 at the Department of Medical Oncology and were analyzed for the above parameters. Surgical procedure followed were staging laparotomy and unilateral salpingo- ophorectomy or total abdominal hysterectomy and bilateral salpingo ophorectomy in those patients who had completed their family. Peritoneal biopsies, omentectomy and peritoneal washings were performed in those patients in whom disease extended to abdomen.

Systemic chemotherapy consisted of standard BEP combination chemotherapy given every 3 weeks with Inj. Bleomycin $30 \mathrm{u}$ administered IV bolus on days 1,8 and 15, Inj. Etoposide $100 \mathrm{mg} / \mathrm{m} 2 \mathrm{IV}$ infusion on days 1 to 5 and Inj. Cisplatin $20 \mathrm{mg} / \mathrm{m} 2 \mathrm{IV}$ infusion on days 1 to 5 with appropriate pre-hydration and post-hydration, given every 3 weeks for 3 to 4 cycles depending upon risk stratification.

All patients were followed for every 2 months with abdomino pelvic ultrasound, Serum tumour markers every 3months, CT scan Abdomen and pelvis every 6 monts in the first year and second year. From the third year to fifth year they were followed with ultrasound abdomen every 4months and serum tumour markers every 6months and annual CT scan Abdomen and pelvis.

\section{RESULTS}

Between January 2012 and December 2015, 21 patients with malignant germ cell tumours of ovary were treated at Department of Medical Oncology, Institute of Obstetrics and Gynaecology.

Age of the patients ranged between 14 years to 40 years, median age being 21 years. 12 patients were unmarried, and 3 patients presented with germ cell tumour complicating pregnancy.

Abdominal pain was the most common clinical presentation seen in 14 patients $(66 \%)$ and 3 patients $(14 \%)$ presented with abdominal mass. Other symptomatology included irregular menstruation, gastrointestinal disturbances and urinary symptoms. 3 
patients with germ cell tumour complicating pregnancy had abdominal mass detected on ultrasound abdomen done during antenatal check-up.

Table 1: Patient and histopathological characteristics.

\begin{tabular}{|ll|}
\hline Variables & No. of patients (\%) $n=21$ \\
\hline Age (years) & Median 21 \\
\hline Range histology & $14-40$ \\
\hline Dysgerminoma & $6(29 \%)$ \\
\hline Stage & \\
\hline I & $13(62 \%)$ \\
\hline II & $3(14 \%)$ \\
\hline III & $5(24 \%)$ \\
\hline IV & 0 \\
\hline
\end{tabular}

Abdomen examination revealed palpable mass in 12 patients size varying from 12 to $18 \mathrm{~cm} \times 14$ to $20 \mathrm{cms}$. No patients presented with ascites or enlarged left supraclavicular lymph nodes.

Table 2: Tumour markers.

\begin{tabular}{|ll|}
\hline Tumour markers & No. of patients $(\%) n=21$ \\
\hline Elevated Serum AFP & $943 \%)$ \\
\hline Elevated Serum Beta HCG & $3(14 \%)$ \\
\hline $\begin{array}{l}\text { Elevated both AFP and } \\
\text { Beta HCG }\end{array}$ & $4(19 \%)$ \\
\hline Elevated serum LDH & $12(57 \%)$ \\
\hline Normal tumour markers & $5(24 \%)$ \\
\hline
\end{tabular}

Serum AFP was elevated in 9 patients (43\%), Serum beta-HCG was elevated in 3 patients (14\%) and 4 patients had both elevated serum AFP and beta-HCG (19\%). Serum LDH was elevated in 12 patients $(57 \%)$.

Table 3: Surgery characteristics.

\begin{tabular}{|ll|}
\hline Surgical modalities & $\begin{array}{l}\text { No. of Patients }(\%) \\
n=21\end{array}$ \\
\hline Fertility sparing surgery & $15(71 \%)$ \\
\hline TAH and BSO & $4(19 \%)$ \\
\hline Biopsy only & $2(10 \%)$ \\
\hline
\end{tabular}

13 patients $(62 \%)$ presented with Stage I, 5 patients (24\%) with Stage III and 3 patients (14\%) with Stage II.

Surgery-Staging laparotomy represented the initial treatment in all 21 patients $(100 \%)$. Two patients $(10 \%)$ had inoperable disease and had biopsy alone performed. 15 patients $(71 \%)$ had unilateral salpingo- oophorectomy. Total abdominal hysterectomy with bilateral salpingo oophorectomy and infracolic omentectomy were done in 4 patients $(19 \%)$ who had completed family and were willing to undergo hysterectomy.

6 patients $(29 \%)$ had dysgerminoma, 9 patients $(43 \%)$ had mixed germ cell tumour (yolk sac with embryonal carcinoma or Dysgerminoma), 3 patients (14\%) had yolk sac tumour, 3 patients $(14 \%)$ had mature cystic teratoma.

Table 4: Chemotherapy.

\begin{tabular}{|ll|}
\hline Chemotherapy & No. of patients $n=21$ \\
\hline Adjuvant chemotherapy (BEP) & $16(76 \%)$ \\
\hline Neo adjuvant chemotherapy & $2(10 \%)$ \\
\hline No chemotherapy & $3(14 \%)$ \\
\hline Salvage chemotherapy (PVI) & $4(19 \%)$ \\
\hline
\end{tabular}

Adjuvant chemotherapy with BEP regimen was given for 16 patients $(76 \%)$ who had Staging Laparotomy done and as neo-adjuvant in 2 patients (10\%) who had biopsy alone performed. In those 2 patients, there was good response to 3 cycles of BEP and patient had Interval cytoreductive surgery done after neo-adjuvant chemotherapy.

Chemotherapy induced toxicity included nausea and vomiting in 16 patients $(76 \%)$, alopecia in 18 patients $(85 \%)$, grade1 and grade 2 neutropenia in 12 patients $(57 \%)$ and diarrhea in 5 patients $(24 \%)$.

Table 5: Treatment outcomes on follow up.

\begin{tabular}{|ll|}
\hline $\begin{array}{l}\text { Treatment outcome } \\
\text { 2yrs follow-up }\end{array}$ & $\begin{array}{l}\text { No. of patients } \\
n=21\end{array}$ \\
\hline No evidence of disease & $17(81 \%)$ \\
\hline Local abdominal recurrence & $4(19 \%)$ \\
\hline Distant metastasis & 0 \\
\hline
\end{tabular}

The follow up period ranged between 6 months to 5 years after completion of treatment. 4 patients (19\%) presented with recurrence 2 years after completion of treatment. There was no relapse in dysgerminoma or mature cystic teratoma.

3 patients (14\%) with mixed germ cell tumour and 1 patient $(5 \%)$ with yolk sac tumour developed recurrence. All the recurrence patients were treated with salvage chemotherapy (PVI regimen). 2 patients had responded and on regular follow up. 2 patients defaulted after starting chemotherapy and lost for follow up.

Table 6: Chemotherapy toxicities.

\begin{tabular}{|ll|}
\hline Chemotherapy toxicities & No. of patients n=21 \\
\hline Nausea/ vomiting & $16(76 \%)$ \\
\hline Alopecia & $18(85 \%)$ \\
\hline Anemia & $0(43 \%)$ \\
\hline Neutropenia Gr I, Gr II & $12(57 \%)$ \\
\hline Diarrhoea & $5(24 \%)$ \\
\hline
\end{tabular}

During follow up all 15 patients (71\%) who underwent conservative fertility sparing surgery resumed normal menstrual cycles within a median 4 months from completion of treatment. There was no reporting of bleomycin induced pulmonary toxicity. 


\section{DISCUSSION}

Malignant ovarian germ cell tumours are rare and represent only $2 \%$ to $5 \%$ of all ovarian malignancies. ${ }^{12}$ Symptoms and Signs of germ cell tumours are rather typical, it tends to be quite large and rapidly progressive malignancies. Abdominal pain associated with a palpable abdominopelvic mass is observed in almost all patients. ${ }^{13}$

Malignant ovarian germ cell tumours affect generally adolescent and young women with a peak incidence around 20years. ${ }^{14}$ In the present study median age was 21 years and about $10 \%$ of patients were older than 30 years.

In present study mixed germ cell tumour was the commonest histology (43\%) followed by dysgerminoma $(29 \%)$, yolk sac tumour $(14 \%)$ and mature cystic teratoma $(14 \%)$.

Approximately 60 to $70 \%$ of malignant germ cell tumours are diagnosed as FIGO Stage I whereas advanced stages were uncommon. In our study 13 patients $(62 \%)$ presented with Stage I disease, 5patients (24\%) presented with Stage III disease and 3 patients $(14 \%)$ presented with Stage II disease.

The Serum tumour markers are an important factor for the diagnosis of disease and for prediction of early relapse. The alteration of serum b-HCG and AFP preceded the radiological and clinical progression detection in most of the cases. Dimopoulos et al reported elevation of serum AFP in $32 \%$ of patients at diagnosis and serum b-HCG in $18 \%$ of cases but they did not make any correlation between these previously elevated tumour markers and the prognosis or treatment failure. ${ }^{15}$

For patients with apparent Stage Ia pure dysgerminoma management options include Laparoscopic restaging or surveillance. ${ }^{16}$ Further studies are required to establish whether restaging or surveillance is the best approach. Chemotherapy with BEP should be reserved for treatment of relapse with a high cure rate.

The unilateral salphingo-oophorectomy, a fertility sparing surgery did not seem to increase the risk of progression or death related to disease. That is important for the younger population affected by germ cell tumours who is willing to experience child bearing. Kumar et al recently showed a retrospective analysis of 23 patients with advanced germ cell tumours in whom fertility sparing surgery was done after neoadjuvant chemotherapy with BEP regimen. 18 patients could undergo fertility sparing surgery and had resumed menstruation. ${ }^{17}$

Several authors demonstrated that residual disease after initial surgery is a prognostic factor for malignant germ cell tumour patients. ${ }^{18}$ In present study 3 patients $(14 \%)$ who presented with relapse had residual disease after surgery and were stage III at initial presentation.
The introduction of multiagent platinum based chemotherapy has radically improved survival of germ cell tumour patients. At present BEP chemotherapy is indicated in all patients of malignant germ cell tumours with the exception of Stage Ia pure dysgerminoma and immature teratoma Stage Ia gradeI. ${ }^{19}$ However chemotherapy regimen can induce short term and long term adverse effects, but the incidence of severe complications was manageable and acceptable given the high response rate and cure rate of this treatment. ${ }^{20}$ Long term toxicity was not documented in our study.

Recent studies on reproductive function after fertility sparing surgery followed by chemotherapy for malignant germ cell tumours indicated that $80 \%$ to $90 \%$ of patients achieved a normal menstrual function. ${ }^{21}$ In our study all 15 patients $(100 \%)$ who underwent fertility sparing surgery presented full recovery of their menses within a median time of 4 months from treatment termination.

\section{CONCLUSION}

Malignant ovarian germ cell tumours are relatively uncommon neoplasms that are characterized by high chemosentivity. Surgery has an important role in the management of germ cell tumours. Initial careful surgical staging is of great importance for appropriate subsequent therapy. Fertility sparing surgery is feasible in most cases. Malignant ovarian germ cell tumours have excellent prognosis with 5year survival rate of $90 \%$ to $95 \%$ for Stage I and $70 \%$ to $75 \%$ for advanced stages. Despite the great effectiveness of BEP regimen there is a lack of large prospective randomized trials focussing on the definition of reliable prognostic and predictive factors, involving clinical and molecular features and improving survival for patients with advanced and incompletely resected disease. Furthermore, the longterm toxicity impact of BEP is still unknown.

\section{Funding: No funding sources \\ Conflict of interest: None declared \\ Ethical approval: The study was approved by the Institutional Ethics Committee}

\section{REFERENCES}

1. Williams S, Blessing JA, Liao SY, Ball H, Hanjani P. Adjuvant therapy of ovarian germ cell tumors with cisplatin, etoposide, and bleomycin: a trial of the Gynecologic Oncology Group. J Clin Oncol. 1994;12(4):701-6.

2. Tewari K, Cappuccini F, Disaia PJ, Berman ML, Manetta A, Kohler MF. Malignant germ cell tumors of the ovary. Obstet Gynecol. 2000 ;95(1):128-33

3. Gershenson DM, Update on malignant ovarian germ cell tumours, Cancer. 1993:71.1581-90.

4. Williams SD. Treatment of germ cell tumours of the ovary. Seminars in oncol.1991;18:292-6.

5. Bajorin DF, Sarosely MF, Pfister DG. Randomized trial of Etoposide and cisplatin versus etoposide and 
carboplatin in patients with good risk germ cell tumours, a multi institutional study. J Clin Oncol. 1993;11:598-606.

6. Pectasides D, Pectasides E, Kassanos D. Germ cell tumours of the ovary. Cancer Treat Rev. 2008;34:427.

7. Gershenson DM. Management of ovarian germ cell tumours. J Clin Oncol. 2007;25:2938-43.

8. Colombo N, Peiretti M, Castiglione M. Non epithelial ovarian cancer, ESMO clinical recommendation for diagnosis, treatment and followup. Annal Oncol. 2009;4:24-26.

9. Gershenson DM, Morris M, Cangir A, Kavanagh JJ, Stringer CA, Edwards CL, et al. Treatment of malignant germ cell tumours of ovary with bleomycin, etoposide and cisplatin. J Clin Oncol. 1990,8:715-20.

10. Williams SD, Blessing JA, Hatch KD, Homesley HD. Chemotherapy of advanced Dysgerminoma with cisplatin, etopoide and bleomycin, a trial of Gynaecologic Oncology Group. J Clin Oncol. 1991 Nov;9(11):1950-5.

11. Cushing B, Giller R, Ablin A, Cohen L, Cullen J, Hawkins E et al. Surgical treatment alone is effective for ovarian immature teratoma in children and adolescents, a report of pediatric oncology group and the children's cancer group. Am J Obstet Gynecol. 1999;181:353-8.

12. Gershenson DM. Management of early ovarian cancer- germ cell and sex cord stromal tumours, Gynecol Oncol. 1994;55:562-7.

13. Morris HJ, Zirkin HJ, Benson WL. Germ cell tumours of ovary, a clinical and pathological study of 58 cases. Cancer. 1986;68(5)624-9.

14. Quirk JT, Natarajan N, Mettlin CJ. Age specific ovarian cancer incidence rate patterns in United States, Gynaecol Oncol. 2005;99:248-250.
15. Dimopoulos MA, Papadopoulou M, Andecapoulou E, Papadimitriou C, Pavlidis N, Aravantinos G, et al. Favourable outcome of Ovarian germ cell malignancies treated with cisplatin or carboplatin based chemotherapy. Gynecol Oncol. 1998;70:70-74.

16. Billimire D, Vinocur C, Rescorla F, Cushing B, Schlatter M, Davis M, et al. Outcome and staging evaluation in malignant germ cell tumours of ovary in children and adolescents: an Intergroup study. J Pediatric Surg. 2004;49:424-9.

17. Talukdar S, Kumar S, Bhatla N, Mathur S, Thulkar S, Kumar L. Neoadjuvant chemotherapy in treatment of advanced malignant germ cell tumours of ovary. Gynecol Oncol. 2014;132:28-32.

18. Mangili G, Sigismondi C, Gadducci A, Cormio G, Scollo P, Tateo S et al. Outcome and risk factors for recurrence in malignant ovarian germ cell tumors: a MITO-9 retrospective study. Int J Gynecol Cancer. 2011 Nov 1;21(8):1414-21.

19. Williams SD, Brich R, Einhorn LH, Irwin L, Greco FA, Loehrer PJ. Treatment of disseminated Germ cell tumours with Chemotherapy. N Eng J Med. 1987;316:1435-40.

20. Sklar CA, Matens AC, Mitby P, Whitton J, Stovall $\mathrm{M}$, Kasper $\mathrm{C}$ et al. Premature menopause in survivors of childhood cancers, a report from childhood cancer survivor study. J National Cancer Institute. 2006,98:890-896.

21. Brenner M, Gershenson DM, Herzog CE, Mitchell MF, Silva EG, Wharton JT. Outcome and reproductive function after chemotherapy for ovarian dysgerminoma. J Clin Oncol. 1999:17;2670-7.

Cite this article as: Kumar RB, Das V. Treatment outcomes in malignant ovarian germ cell tumors. Int J Reprod Contracept Obstet Gynecol 2017;6: 525660. 